Стародубцева Елена Дмитриевна

аспирант кафедры проектного менеджмента и управления качеством Санкт-Петербургского государственного экономического университета

\section{СОВЕРШЕНСТВОВАНИЕ МЕТОДИКИ ОЦЕНКИ РЕЗУЛЬТАТИВНОСТИ СИСТЕМЫ МЕНЕДЖМЕНТА КАЧЕСТВА НА ПРОМЫШЛЕННОМ ПРЕДПРИЯТИИ}

Аннотация:

В статье рассматривается методика оценки результативности системы менеджмента качества на предприятиях, сертифицированных ГОСТ Р ИСО 9001-2015 и ГОСТ РВ 0015.002-2012. Автор предлагает альтернативную методику оценки результативности СМК промышленного предприятия с учетом особенностей ее формирования и ориентаци на сферу деятельности компании. Кроме того, затрагиваются вопросы управления процессами в рамках жизненного цикла продукции. Деятельность организации подразделяется на процессы менеджмента, основные и обеспечивающие. Тем са мым в рамках методики оценки СМК можно проследить влияние каждой группы процессов на результативность системы в иелом. Для той или иной группы подбираются критерии оценки. Разработанный механизм апробирован в ООО «НеоТех» и практически применим на других промышленных предприятиях.

Ключевые слова

система менеджмента качества, управление качеством, процессный подход, анализ СМК, результативность, показатель результативности, стандарт качества, промышленное предприятие.
Starodubtseva Elena Dmitrievna

PhD student, Project and Quality Management Department

St. Petersburg State University of Economics

\section{IMPROVING PERFORMANCE MEASUREMENT METHODS \\ FOR A QUALITY MANAGEMENT SYSTEM IN AN INDUSTRIAL COMPANY}

Summary:

The study discusses the methods for measuring the performance of the quality management system in companies certified according to ISO and national military standard in Russia. The author proposes an alternative method of measuring the QMS performance of an industrial company in view of the characteristics of the QMS and the scope of the company's activities. In addition, the paper deals with the process management within the product life cycle. There are management, basic, and supporting processes in the company's activities. Thus, within the framework of the QMS mea-surement methods, one can trace the impact of each group of processes on the system performance as a whole. Evaluation criteria are selected for a group. The mechanism developed has been tested in NeoTech, 000 (Russia) and can be applied to any industrial company.

Keywords: quality management system, quality management, process approach, QMS analysis, performance, performance indicator, quality standard, industrial company.

Система менеджмента качества (далее - СМК) представляет собой универсальный инструмент, позволяющий предприятиям создавать возможности для выпуска качественной продукции. Руководство компании, внедряя СМК, планирует достичь конкретных результатов за определенный период. Для решения данной задачи необходимо выявить типовые процессы, подлежащие оценке, проанализировать их количественные показатели [1]. Согласно ГОСТ Р ИСО 9001-2015 предприятие должно установить процессы, которые можно измерить, а также выбрать или сформировать метод для исследования и измерения параметров качества, что будет обеспечивать достоверный результат и соблюдение сроков проведения мониторинга [2].

В свою очередь мониторинг данных даст возможность определить сильные и слабые стороны СМК предприятия и найти пути для их развития. При внедрении стандарта ГОСТ PB 0015.002-2012 встает вопрос об обязательном формировании методики оценки результативности СМК [3]. Важно отметить, что компания может разработать свою уникальную методику такой оценки, в рамках которой будут анализироваться наиболее важные для конкретной организации параметры.

Актуальность темы исследования определяется интенсификацией внедрения стандартов СМК ГОСТ Р ИСО 9001-2015 и ГОСТ РВ 0015.002-2012 на промышленных предприятиях, что приводит к необходимости формирования для них методики оценки результативности СМК. В рамках такой методики может изучаться действенность производственной системы.

При рассмотрении существующих методик оценки результативности СМК следует отметить разработанную координационным советом систему добровольной сертификации «Военный регистр» [4]. Согласно данной методике выделяются частные показатели СМК, которые делятся на 
два уровня [4]. К первому относятся параметры, характеризуемые соответствием СМК предприятия требованиям ГОСТ РВ 0015.002, в частности удовлетворенность потребителей, соответствие требованиям продукции, степень выполнения ГОСТ РВ 15.002, степень достижения целей области качества, качество продукции поставщика [5]. Критерии второго уровня определяют процесс приемки, а именно: доля актов приемки научно-исследовательских работ (НИР), опытно-конструкторские работы (ОКР), не содержащие замечаний заказчика, доля продукции, сданной с первого предъявления заказчику, количество полученных рекламаций, число полученных претензий от заказчика. В дальнейшем показатели оцениваются по формулам, представленным в методике.

Данная методика разработана для предприятий, работающих по гособоронзаказам. При подготовке методики оценки результативности для ООО «НеоТех» использовались некоторые фракторы результативности из методики «Военного регистра» [6].

В существующих методиках оценки результативности СМК предприятий основное внимание уделяется выделению производственных процессов, их группировке и параметрам оценки [7]. Анализ действенности СМК следует разделить на несколько этапов [8]:

- разработка критериев;

- оценка результативности процессов;

- оценка процессов по шкале значимости;

- определение значений показателей СМк;

- анализ устойчивости системы;

- принятие решений по управлению СМК.

При исследовании существующих методик оценки результативности СМК нужно отметить, что в этом случае необходимо выделить важнейшие для предприятия процессы, которые можно определить количественными показателями, а также задать критерии оценки. После анализа делается вывод о возможностях улучшения СМК.

Под результативностью системы менеджмента качества понимается степень реализации запланированных мероприятий по улучшению качества и достижению показателей качества в рамках деятельности предприятия [9]. Оценка действенности СМК носит индивидуальный характер для каждой конкретной компании. Цели разработки и внедрения методики на промышленном предприятии состоят в получении объективных и актуальных данных о состоянии СМК в определенный период и в конечном счете в поиске сильных и слабых сторон СМК [10, с. 84].

Первым этапом разработки методики оценки результативности является выделение типовых процессов предприятия. Под процессом понимается определенная последовательность действий, которая преобразует входы (начало процесса) в выходы (его окончание) [11]. Процессы можно разделить на три группы: процессы менеджмента, основные процессы и обеспечивающие процессы.

Процессы менеджмента отражают действия управленческого аппарата (менеджеров), которые обеспечивают осуществление основных процессов предприятия. Эти процессы напрямую зависят от сферы работы компании и отвечают за жизненный цикл продукции от маркетинговых исследований до реализации и последующей утилизации. Обеспечивающие процессы являются вспомогательными и поддерживают главные процессы жизненного цикла системы.

В данном исследовании представлена методика оценки результативности предприятия электронной промышленности ООО «НеоТех», областью деятельности которого являются разработка и производство электрощитового оборудования, прямые поставки зарубежных электрокомпонентов. Ключевой особенностью деятельности компании выступает ориентация как на выпуск (инициативные разработки), так и на перепродажу зарубежных компонентов и изделий. Поэтому самыми важными процессами для ООО «НеоТех» служат ОКР, закупка, производство и продажа. Закупка - основной процесс, поскольку организации необходимо закупить электрокомпоненты для перепродажи и обеспечить производство качественными элементами и расходными материалами.

Методика оценки результативности СМК разработана в соответствии с особенностями сферы деятельности ООО «НеоТех» и состоит из нескольких этапов:

- выбор типовых процессов для оценки;

- разделение процессов на группы (процессы менеджмента, основные процессы, обеспечивающие процессы);

- анализ результативности каждой группы;

- оценка результативности СМК.

В качестве исходных данных выступают независимые оценки экспертов ООО «НеоТех», которые являются членами совета по качеству предприятия, в частности генерального директора, коммерческого директора, директора по маркетингу, руководителя отдела закупок, технического директора, начальника производства, начальника ОТК, начальника склада, ведущего инженера, менеджера по качеству. Регламентирующими документами, отражающими качество выполнения анализируемых процессов, при проведении экспертной оценки служат стандарты предприятия. 
Минимальное значение оценки экспертов - 0 (ноль), максимальное - 1 (единица). Результативность каждой группы определяется в соответствии с итогами мониторинга процессов руководителями подразделений в рамках ежегодной оценки СМК. Использование шкалы оценки экспертов обосновано удобством и наглядностью проведения дальнейшего расчета.

В ходе анализа каждому показателю группы присваивается оценка в соответствии со степенью выполнения. Параметры для оценки определяются на совещании совета по качеству ООО «НеоТех». Оценки показателей по группам процессов для расчета результативности СМК по предложенной методике сведены в таблицы 1-3. Критерии могут подразделяться на группы в связи с особенностями производства. В рамках данной методики показатели имеют равное значение.

В исследовании к менеджменту отнесены следующие процессы: планирование (M1), управление рисками (M2), анализ СМК со стороны руководства (М3) и внутренний аудит (M4). Выполнение планов отделов по качеству при планировании (M1) оценивается в 1 балл, невыполнение - 0. Показатели процессов менеджмента приведены в таблице 1. Результативность всех трех типовых процессов $R_{\text {j }}$ равняется отношению суммы параметров к их количеству и вычисляется по следующей формуле:

$$
R_{j}=\frac{\sum_{i=1}^{n} x_{i}}{n}(\mathrm{j}=1,2,3),
$$

где $\mathrm{n}$ - количество показателей (для каждого процесса разное);

$\mathrm{xj}$ - величина ј-го показателя - результат конкретного измерения.

Таблица 1 - Оценка показателей процесса менеджмента $R_{1}$

\begin{tabular}{|c|c|c|}
\hline Показатель & Значение & Расчет \\
\hline М1 Планирование & \multicolumn{2}{|c|}{$\begin{array}{l}\text { При выполнении планов по качеству подразделений предприятия } \\
\text { (М1.1 - М1.9) ставится 1, при невыполнении - }\end{array}$} \\
\hline М1.1 Производство (отдел) & & 1 \\
\hline M1.2 OTK & & 1 \\
\hline М1.3 Служба качества & & 1 \\
\hline М1.4 Отдел продаж & & 1 \\
\hline $\begin{array}{l}\text { М1.5 Отдел закупок } \\
\text { для производства }\end{array}$ & & 1 \\
\hline М1.6 Отдел кадров & & 1 \\
\hline $\begin{array}{l}\text { М1.7 Административный } \\
\text { отдел }\end{array}$ & & 1 \\
\hline М1.8 Склад (отдел) & & 1 \\
\hline \multirow[t]{2}{*}{ М1.9 Отдел маркетинга } & & 1 \\
\hline & Среднее значение показателей М1 & $x_{1}=9 / 9=1$ \\
\hline \multicolumn{3}{|c|}{$\begin{array}{l}\text { М2 Управление рисками (Рассматривается процесс управления рисками, которые предприятие выделило } \\
\text { для контроля и мониторинга в рамках ежегодной оценки рисков. Оценка риска в ООО «НеоТех» пред- } \\
\text { ставляет собой совокупность вероятности возникновения неопределенности и тяжести ее последствий) }\end{array}$} \\
\hline $\begin{array}{l}\text { М2.1 Заполнение карт } \\
\text { рисков }\end{array}$ & $\begin{array}{l}\text { При заполнении карт рисков присваивается } 1 \text { балл, при } \\
\text { незаполнении - } 0\end{array}$ & $x_{2}=1$ \\
\hline $\begin{array}{l}\text { М2.2 Выполнение меропри- } \\
\text { ятий по снижению риска }\end{array}$ & $\begin{array}{l}\text { Количество выполненных мероприятий (18) / количество } \\
\text { запланированных мероприятий (20) }\end{array}$ & $x_{3}=18 / 20=0,90$ \\
\hline М2.3 Контроль рисков & $\begin{array}{l}\text { Количество сниженных рисков (36) / количество выяв- } \\
\text { ленных рисков (40) }\end{array}$ & $x_{4}=36 / 40=0,90$ \\
\hline $\begin{array}{l}\text { МЗ Анализ СМК со стороны } \\
\text { руководства }\end{array}$ & $\begin{array}{l}\text { При проведении анализа присваивается } 1 \text { балл, при не- } \\
\text { проведении - } 0\end{array}$ & $x_{5}=1$ \\
\hline \multicolumn{3}{|l|}{ М4 Внутренний аудит } \\
\hline $\begin{array}{l}\text { М4.1 Планирование } \\
\text { внутреннего аудита }\end{array}$ & $\begin{array}{l}\text { Количество проведенных внутренних аудитов (2) / коли- } \\
\text { чество запланированных внутренних аудитов (2) }\end{array}$ & $x_{6}=2 / 2=1$ \\
\hline $\begin{array}{l}\text { М4.2 Охват подразделений } \\
\text { в процессе внутреннего } \\
\text { аудита }\end{array}$ & $\begin{array}{l}\text { Количество проверенных подразделений (9) / количе- } \\
\text { ство подразделений (9) }\end{array}$ & $x_{7}=9 / 9=1$ \\
\hline $\begin{array}{l}\text { М4.3 Результаты } \\
\text { внутреннего аудита }\end{array}$ & $\begin{array}{l}\text { Количество несоответствий (18) / количество соответ- } \\
\text { ствий }(30)\end{array}$ & $x_{8}=8 / 30=0,60$ \\
\hline $\begin{array}{l}\text { М4.4 Доля повторных } \\
\text { несоответствий }\end{array}$ & $\begin{array}{l}\text { Количество повторных несоответствий (5) / количество } \\
\text { соответствий (18) }\end{array}$ & $x_{9}=5 / 18=0,28$ \\
\hline $\begin{array}{l}\text { М4.5 Корректирующие } \\
\text { и предупреждающие } \\
\text { действия (КиПД) }\end{array}$ & $\begin{array}{l}\text { Количество несоответствий, не исправленных по плану } \\
\text { КиПД (26) / количество исправленных по плану КиПД } \\
(30)\end{array}$ & $\begin{array}{l}x_{10}=26 / 30= \\
0,87\end{array}$ \\
\hline $\begin{array}{l}\text { Результативность } \\
\text { процессов менеджмента }\end{array}$ & Сумма показателей $(8,55)$ / количество показателей $(10)$ & $R_{1}=0,85$ \\
\hline
\end{tabular}


Пример расчета оценок показателей процесса менеджмента $\mathrm{R}_{1}$, согласно формуле (1), выглядит следующим образом:

$$
\begin{gathered}
R_{1}=\frac{\sum_{i=1}^{n} x_{i}}{n}=\left(x_{1}+x_{2}+x_{3}+x_{4}+x_{5}+x_{6}+x_{7}+x_{8}+x_{9}+x_{10}\right) / 10= \\
=(1+1+0,90+0,90+1+1+1+0,60+0,28+0,87) / 10=0,85(\text { при } n=10) .
\end{gathered}
$$

К основным процессам относятся маркетинговые исследования (П1), ОКР (П2), производство (П3), закупка (П4), входной контроль (П5), ОТК (П6), складирование (П7), оценка удовлетворенности потребителей (П7). Показатели основных процессов приведены в таблице 2.

\begin{tabular}{|c|c|c|}
\hline Показатель & Значение & Расчет \\
\hline \multicolumn{3}{|c|}{ П1 Маркетинговые исследования } \\
\hline $\begin{array}{l}\text { П1.1 Оценка внешней и внут- } \\
\text { ренней среды }\end{array}$ & $\begin{array}{l}\text { При проведении оценки присваивается } 1 \text { балл, } \\
\text { при непроведении - } 0\end{array}$ & $x_{1}=1$ \\
\hline \multicolumn{3}{|l|}{ П2 ОКР } \\
\hline $\begin{array}{l}\text { П2.1 Управление конструк- } \\
\text { торской документацией (КД) }\end{array}$ & $\begin{array}{l}\text { Превышение сроков разработки КД - отношение фак- } \\
\text { тических сроков (15) / к плановым (25) }\end{array}$ & $x_{2}=15 / 25=0,60$ \\
\hline $\begin{array}{l}\text { П2.2 Управление технологи- } \\
\text { ческой документацией (ТД) }\end{array}$ & $\begin{array}{l}\text { Превышение сроков разработки ТД - отношение фак- } \\
\text { тических сроков (26) / к плановым (30) }\end{array}$ & $x_{3}=26 / 30=0,87$ \\
\hline ПЗ Производство & $\begin{array}{l}\text { Задержка отгрузки продукции (12) / отгрузка изготов- } \\
\text { ленной продукции в срок (28) }\end{array}$ & $x_{4}=12 / 28=0,43$ \\
\hline П4 Закупка & $\begin{array}{l}\text { Количество предъявленных рекламаций поставщику } \\
\text { (24)/ количество закупленной продукции (количество } \\
\text { счетов) (180) }\end{array}$ & $x_{5}=24 / 180=0,14$ \\
\hline П5 Входной контроль & $\begin{array}{l}\text { Количество несоответствий (24) / количество соот- } \\
\text { ветствий (200) }\end{array}$ & $x_{6}=24 / 200=0,13$ \\
\hline П6 ОТК & $\begin{array}{l}\text { Количество забракованных в процессе производства } \\
\text { изделий (14) / количество выпущенных изделий (26) }\end{array}$ & $x_{7}=14 / 26=0,55$ \\
\hline $\begin{array}{l}\text { П7 Оценка удовлетворенно- } \\
\text { сти потребителей }\end{array}$ & $\begin{array}{l}\text { При проведении оценки присваивается } 1 \text { балл, при } \\
\text { непроведении - } 0\end{array}$ & $x_{8}=1$ \\
\hline $\begin{array}{l}\text { Результативность } \\
\text { основного процесса }\end{array}$ & Сумма показателей $(4,72)$ / количество показателей $(8)$ & $R_{2}=0,59$ \\
\hline
\end{tabular}

\section{Таблица 2 - Оценка показателей основного процесса $\boldsymbol{R}_{\mathbf{2}}$}

Пример расчета оценок показателей основного процесса $R_{2}$ выглядит следующим образом:

$$
\begin{gathered}
R_{2}=\frac{\sum_{i=1}^{n} x_{i}}{n}=\left(x_{1}+x_{2}+x_{3}+x_{4}+x_{5}+x_{6}+x_{7}+x_{8}\right) / 8= \\
=(1+0,60+0,87+0,43+0,14+0,13+0,55+1) / 8=0,59(\text { при } n=8) .
\end{gathered}
$$

К обеспечивающим процессам можно отнести управление документацией СМК (О1), управление знаниями (О2), обучение и подбор персонала (О3), метрологическое обеспечение (О4), управление несоответствиями (О5), управление собственностью потребителя (О6), управление рекламациями (O7), делопроизводство (О8). Показатели обеспечивающих процессов приведены в таблице 3.

Таблица 3 - Оценка показателей обеспечивающего процесса $R_{3}$

\begin{tabular}{|l|l|l|}
\hline \multicolumn{1}{|c|}{ Показатель } & \multicolumn{1}{|c|}{ Значение } & Расчет \\
\hline $\begin{array}{l}\text { О1 Управление } \\
\text { документацией СМК }\end{array}$ & $\begin{array}{l}\text { Количество просмотренных документов (21)/ количе- } \\
\text { ство документов, запланированных к просмотру (26) }\end{array}$ & $x_{1}=21 / 26=0,80$ \\
\hline О2 Управление знаниями & $\begin{array}{l}\text { Количество сотрудников, прошедших обучение (17) / } \\
\text { общее количество сотрудников (35) }\end{array}$ & $x_{2}=17 / 35=0,50$ \\
\hline О3 Обучение персонала & $\begin{array}{l}\text { Количество аттестованных сотрудников (8) / количе- } \\
\text { ство сотрудников, подлежащих аттестации (15) }\end{array}$ & $x_{3}=8 / 15=0,50$ \\
\hline О4 Метрология & $\begin{array}{l}\text { Количество поверенных приборов (20)/ количество за- } \\
\text { планированных коверке приборов (20) }\end{array}$ & $x_{4}=20 / 20=1$ \\
\hline $\begin{array}{l}\text { О5 Управление } \\
\text { несоответствиями }\end{array}$ & $\begin{array}{l}\text { Количество выполненных мероприятий по предупрежде- } \\
\text { нию несоответствий (8) / количество запланированных } \\
\text { мероприятий по предупреждению несоответствий (11) }\end{array}$ & $x_{5}=8 / 11=0,70$ \\
\hline $\begin{array}{l}\text { О6 Управление } \\
\text { собственностью потребителя }\end{array}$ & $\begin{array}{l}\text { Количество проектов, выполненных по чертежам за- } \\
\text { казчика (14) / количество проектов, выполненных по } \\
\text { чертежам ОоО «НеоТех» (26) }\end{array}$ & $x_{6}=14 / 26=0,53$ \\
\hline $\begin{array}{l}\text { О7 Управление } \\
\text { рекламациями }\end{array}$ & $\begin{array}{l}\text { Количество полученных рекламаций (7) / количество } \\
\text { удовлетворенных рекламаций (9) }\end{array}$ & $x_{7}=7 / 9=0,77$ \\
\hline О8 Делопроизводство & $\begin{array}{l}\text { Количество исполненных приказов в срок (19) / количе- } \\
\text { ство выпущенных приказов (23) }\end{array}$ & $x_{8}=19 / 23=0,80$ \\
\hline $\begin{array}{l}\text { Результативность } \\
\text { обеспечивающих процессов }\end{array}$ & Сумма показателей (5,6) / количество показателей (8) & $R_{3}=0,70$ \\
\hline
\end{tabular}

Далее представлен пример расчета оценок показателей обеспечивающего процесса $\mathrm{R}_{3}$ : 


$$
\begin{gathered}
R_{3}=\frac{\sum_{i=1}^{n} x_{i}}{n}=\left(x_{1}+x_{2}+x_{3}+x_{4}+x_{5}+x_{6}+x_{7}+x_{8}\right) / 8= \\
=(0,80+0,50+0,50+1+0,70+0,53+0,77+0,80) / 8=0,70(\text { при } n=8) .
\end{gathered}
$$

Результативность СМК вычисляется по следующей формуле:

$$
R=\sum_{j=1}^{k} R_{j}=R_{1}+R_{2}+R_{3}(k=1,2,3),
$$

где $R$ - результативность СМК;

$R_{j}$ - результативность типового процесса;

$k$ - количество типовых процессов.

Итоговая результативность СМК ООО «НеоТех» по фрормуле (2) равна: $R=R_{1}+R_{2}+R_{3}=$ $=(0,85+0,59+0,70) / 3=0,71$.

Интерпретация полученного значения результативности СМК с учетом диапазона оценок приведена в таблице 4. За основу интерпретации показателей и характеристик взята методика СДС «Военный регистр» [12].

Таблица 4 - Интерпретация результатов исследования

\begin{tabular}{|l|l|}
\hline \multicolumn{1}{|c|}{$R$} & \multicolumn{1}{|c|}{ Характеристика $R$} \\
\hline Меньше 0,60 & Нерезультативно \\
\hline От 0,60 до 0,75 & Удовлетворительно \\
\hline От 0,75 до 0,95 & Хорошо \\
\hline Больше 0,95 & Отлично \\
\hline
\end{tabular}

Разработанная методика оценки результативности позволяет рассмотреть сильные и слабые стороны процессов предприятия и определить, какие из них влияют на результативность СМК в целом. Как показали исследования, результативность СМК ООО «НеоТех» является удовлетворительной, соответственно, компании необходимо работать над улучшением системы менеджмента качества. Анализ позволил выявить, что наименьшей действенностью обладают процессы менеджмента и основные процессы организации.

В рамках исследования процессов менеджмента выяснено, что в ходе внутренних аудитов обнаруживаются повторные несоответствия, что сказывается на качестве исполнения плана корректирующих и предупреждающих действий. Следовательно, на предприятии необходимо тщательнее контролировать коррекцию и предупреждение несоответствий путем проведения внеплановых аудиторских проверок тех процессов, которые требуют дополнительного внимания. Также нужно отметить, что в более пристальном наблюдении нуждаются процессы производства и закупки. Данное обстоятельство подтверждается анализом результативности основных процессов компании.

Таким образом, представленная методика практически применима на промышленных предприятиях, однако при том условии, что руководство или совет по качеству выделяют типовые процессы и ключевые показатели для оценки их качества.

\section{Ссылки:}

1. Blanco-Encomienda F.J., Rosillo-Díaz E., Muñoz-Rosas J.F. Importance of Quality Control Implementation in the Production Process of a Company // European Journal of Economics and Business Studies. 2018. Vol. 4, no. 1. P. $240-244$. https://doi.org/10.2478/ejes-2018-0027.

2. ГОСТ Р ИСО 9001-2015. Системы менеджмента качества. Требования. М., 2015. 34 с.

3. ГОСТ РВ 0015-002-2012. Системы менеджмента качества. Общие требования. М., 2012. 38 с.

4. Методика оценки результативности системы менеджмента качества организации : утв. решением Координационного совета Системы добровольной сертификации «Военный регистр» : протокол № 6 от 11 апр. 2012 г. М., 2012. 17 с.

5. Там же.

6. Там же.

7. Методика оценки результативности системы менеджмента качества ФГБОУ ВО «САМГТУ НИИ ПКВТ» / И.А. Абдуллин, Е.Л. Москвичева, О.В. Соловейко, А.В. Серкова, М.Д. Федорова, Г.Г. Богатеев // Вестник технологического университета. 2016. Т. 19, № 24. С. 102-105.

8. Искандерова Р.Р. Методика оценки результативности СМК предприятия // Молодой ученый. 2015. № 5. С. 278-280.

9. ГОСТ Р ИСО 9000-2015. Системы менеджмента качества. Основные положения и словарь. М., 2015. 53 с.

10. Проектирование системы менеджмента качества промышленного предприятия : монография / Б.И. Герасимов, И.А. Воеводина, Е.В. Нижегородов, А.А. Попов, А.Ю. Сизикин, Г.А. Соседов. Тамбов, 2013. 227 с.

11. ГОСТ Р ИСО $9000-2015 \ldots$

12. Методика оценки результативности системы менеджмента качества организации ...

\section{References:}

Abdulin, IA, Moskvicheva, EL, Soloveyko, OV, Serkova, AV, Fedotova, MD \& Bogateev, GG 2015, 'QMS Performance Measurement Methods of the Research Institute for Conversion and High Technology of Samara Technical University', Vestnik tekhnologicheskogo universiteta, vol. 19, no. 24, pp. 102-105, (in Russian).

Blanco-Encomienda, FJ, Rosillo-Díaz, E \& Muñoz-Rosas, JF 2018, 'Importance of Quality Control Implementation in the 
Production Process of a Company', European Journal of Economics and Business Studies, vol. 4, no. 1, pp. 240-244, https://doi.org/10.2478/ejes-2018-0027.

Gerasimov, BI, Voevodina, IA, Nizhegorodov, EV, Popov, AA, Sizikin, AYu \& Sosedov, GA 2013, Design of a Quality Management System of an Industrial Company: Monograph, Tambov, 227 p., (in Russian).

Iskanderova, RR 2015, 'Measurement Methods of Company's QMS Performance', Molodoy uchenyy, no. 5, pp. 278-280, (in Russian). 